\title{
FleaTickRisk: a meteorological model developed to monitor and predict the activity and density of three tick species and the cat flea in Europe
}

\author{
Frédéric Beugnet ${ }^{1}$, Karine Chalvet-Monfray ${ }^{2}$, Harilaos Loukos ${ }^{3}$ \\ ${ }^{1}$ Merial, 29 Av T. Garnier, 69007 Lyon, France; ${ }^{2}$ INRA, UR346 d'Epidémiologie Animale, F63122 Saint \\ Genès Champanelle, France; ${ }^{3}$ Climpact, 79 Rue du Faubourg Poissonnière, 75009 Paris, France
}

\begin{abstract}
Mathematical modelling is quite a recent tool in epidemiology. Geographical information system (GIS) combined with remote sensing (data collection and analysis) provide valuable models, but the integration of climatologic models in parasitology and epidemiology is less common. The aim of our model, called "FleaTickRisk", was to use meteorological data and forecasts to monitor the activity and density of some arthropods. Our parasitological model uses the Weather Research and Forecasting (WRF) meteorological model integrating biological parameters. The WRF model provides a temperature and humidity picture four times a day (at 6:00, 12:00, 18:00 and 24:00 hours). Its geographical resolution is $27 \times 27 \mathrm{~km}$ over Europe (area between longitudes $10.5^{\circ} \mathrm{W}$ and $30^{\circ} \mathrm{E}$ and latitudes $37.75^{\circ} \mathrm{N}$ and $62^{\circ} \mathrm{N}$ ). The model also provides weekly forecasts. Past data were compared and revalidated using current meteorological data generated by ground stations and weather satellites. The WRF model also includes geographical information stemming from United States Geophysical Survey biotope maps with a 30" spatial resolution (approximately $900 \times 900 \mathrm{~m}$ ). WRF takes into account specific climatic conditions due to valleys, altitudes, lakes and wind specificities. The biological parameters of Ixodes ricinus, Dermacentor reticulatus, Rhipicephalus sanguineus and Ctenocephalides felis felis were transformed into a matrix of activity. This activity matrix is expressed as a percentage, ranging from 0 to 100 , for each interval of temperature $\mathrm{x}$ humidity. The activity of these arthropods is defined by their ability to infest hosts, take blood meals and reproduce. For each arthropod, the matrix was calculated using existing data collected under optimal temperature and humidity conditions, as well as the timing of the life cycle. The mathematical model integrating both the WRF model (meteorological data + geographical data) and the biological matrix provides two indexes: an activity index (ranging from 0 to 100), calculated for the previous week and predictive for the coming week, and a cumulative index (ranging from 0 to 1000) which takes into account the past 12 weeks. The indexes are calculated twice a day for each geographical point all over Europe and are corrected based on three types of defined biotopes: urban and sub-urban areas, rural areas, and wilderness and forests. To clarify the presentation, indexes are calculated within intervals and are presented as colour maps grouping index isoclines. We hypothesised that the populations of tick and flea hosts are not lacking and therefore do not affect the numbers of arthropods. However, microclimates and biotopes have a major impact, especially on tick populations, and the results provided by the model must therefore be adjusted to local conditions by specialists, such as local veterinarians. Where fleas are concerned, the model takes into account their outdoor activity and ignores their indoor life cycle. The accuracy of the data was verified throughout 2007 and 2008, using sentinel veterinary clinics and tick samples, as well as comparisons with published surveys. The maps constructed with the model are available to veterinary practitioners on www.FleaTickRisk.com.
\end{abstract}

Keywords: mathematical modelling, meteorology, predictive activity, tick, flea.

\section{Introduction}

Corresponding author:

Frédéric Beugnet

Merial, 29 Av T. Garnier, 69007 Lyon, France

Tel. +33 472723 000; Fax +33 472723298

E-mail: Frederic.beugnet@merial.com
Despite increasing treatment rates, cats and dogs are still regularly infested by ticks and fleas (Otranto and Wall, 2008). The role played by these arthropods as vectors of pathogens is well known to vet- 
erinarians and owners. Over the past decade, far from dropping, the number of infestations has grown and more importantly, changes have been seen in the transmitted diseases (Shaw et al., 2001). Numerous reasons have been suggested to explain such changes: (i) increasing travels of carnivores from one region of Europe to another, which may explain the imports of ectoparasites and diseases (Shaw et al., 2003); (ii) lifestyle changes for people and their pets: development of residential areas with gardens, development of parkland, return to nature, trekking, jogging, etc; (iii) wildlife preservation with an increase in the populations of tick hosts (cervids, foxes, wild boars, rodents); and (iv) weather changes mainly characterised by shorter winters (Lindgren and Gustafson, 2001; Marhrenholz, 2008).

In Europe, predicting the risk of infestation by parasites, fleas and ticks, may help improve the implementation of control measures (frequency of treatments), but may also lead clinicians to consider vector-borne diseases sooner. Clearly, spatio-temporal modelling is becoming an increasingly important tool for the study and follow-up of arthropod vectors, diseases, or any factor which may have an impact on health (Rizzoli et al., 2007; Marechal et al., 2008). Veterinary medicine will use more and more modelbased epidemiological tools (Rinaldi et al., 2006). In parasitology, studies have already been performed on canine cardiopulmonary dirofilariosis (Mortarino et al., 2008), various species of mosquitoes or midges, West Nile fever and Bluetongue. Mathematical models of the dynamics of fleas and certain species of ticks have been created, based on their life cycles and parameters likely to be involved (Beugnet et al., 1998, 2004). Several teams have studied the distribution and risk of infestation by ticks, demonstrating the advantages of combining spatial data and climatic data (Estrada-Peña and Venzal, 2007; Estrada-Peña, 2008; Estrada-Peña et al., 2008). The difficulty is to have access in real time to reliable meteorological forecasts (ground temperature and humidity) over an extended geographical area. The collaboration between researchers in meteorology, biomathematics and parasitology helped us develop a bio-meteoro- logical model to evaluate the activity and probability of density of certain species of ticks and of the cat flea (Beugnet et al., 2008). This tool will be made available to veterinarians through an Internet site (www.fleatickrisk.com), to help them improve their advice to animal owners. The high-resolution Weather Research and Forecasting (WRF) model, which provides temperature and humidity readings combined with the plant cover and level of urbanization, is used to predict the average activity of certain arthropod vectors, by integrating into matrices biological activity data (moulting, egg laying, host finding) of the three main tick species in Europe (Ixodes ricinus, Dermacentor reticulatus and Rhipicephalus sanguineus) and of the cat flea (Ctenocephalides felis felis). This model thus provides two bio-climatic indexes: (i) an index of weekly activity, forecasting the coming week and describing the previous week, ranging from 0 to 100; and (ii) an index of cumulated activity over 12 weeks (thus providing an idea of density), ranging from 0 to 1,000 .

The forecasting bio-climatic model focuses on a geographical area of 27 by $27 \mathrm{~km}$, to which is then applied a $1 \mathrm{~km}^{2}$ geographical filter, to help make adjustments based on three predefined biotopes.

It is important to note that this model is not a geographical information system (GIS) biotope model but a meteorological model. It does neither indicate a suitability index to predict the ability nor different tick species to be present. It indicates the rate of activity ("turn-over") in biotopes that are suitable for the concerned tick. Knowing the local biotopes and the importance of micro-biotope for ticks, an interpretation is necessary. It is neither a climatic model looking at the changes that might appear in the geographical distribution of tick species.

\section{Materials and methods}

\section{WRF climatic model}

The WRF model is considered as the successor of the fifth generation meso-scale model (MM5) 
(Michakales et al., 2001; Skamarock et al., 2008). The WRF model resulted from a collaboration between several US institutions, mainly the National Center for Atmospheric Research (NCAR), the National Oceanic and Atmospheric Administration, the National Centers for Environmental Prediction (NCEP), the Forecast Systems Laboratory (FSL), the Air Force Weather Agency (AFWA), the Naval Research Laboratory, the University of Oklahoma and the Federal Aviation Administration (FAA). Two development paths were used, based on two different dynamic integration concepts, the Advanced Research WRF (ARW) developed and maintained by the NCAR Mesoscale and Microscale Meteorology Division, and the Nonhydrostatic Mesoscale Model (NMM) developed by NCEP (Anthes and Warner, 1978; Wicker and Skamarock, 2002). WRF is a limited-area mesoscale meteorological model. It provides meteorological forecasts with resolutions ranging from a few meters to several thousand kilometres over a pre-determined geographical zone. Therefore, it needs to be run by forecasts obtained using a model with a finer resolution and a domain incorporating its own (mostly an atmospheric general circulation model). In addition, WRF is able to function with embedded domains (geographical zones) whose horizontal resolution increases from a parent domain to the child domain it encompasses.

For the purposes of our project, the model functions without embedding, as its sole domain is Europe, located between longitudes $10.5^{\circ} \mathrm{W}$ and $30^{\circ} \mathrm{E}$ and latitudes $37.75^{\circ} \mathrm{N}$ and $62^{\circ} \mathrm{N}$, with a horizontal resolution of approximately $27 \mathrm{~km}$ (Fig. 1). The vertical resolution includes 25 levels unevenly distributed between the ground and the altitude where atmospheric pressure is $100 \mathrm{hPa}$. The levels, corresponding to the vertical coordinates, follow the terrain to start with, then flatten out as altitude increases.

WRF is run every 6 hours with the data of the US Global Forecast System (GFS), with resolutions of $1^{\circ} \times 1^{\circ}(\sim 100 \mathrm{~km}$ at average latitudes).

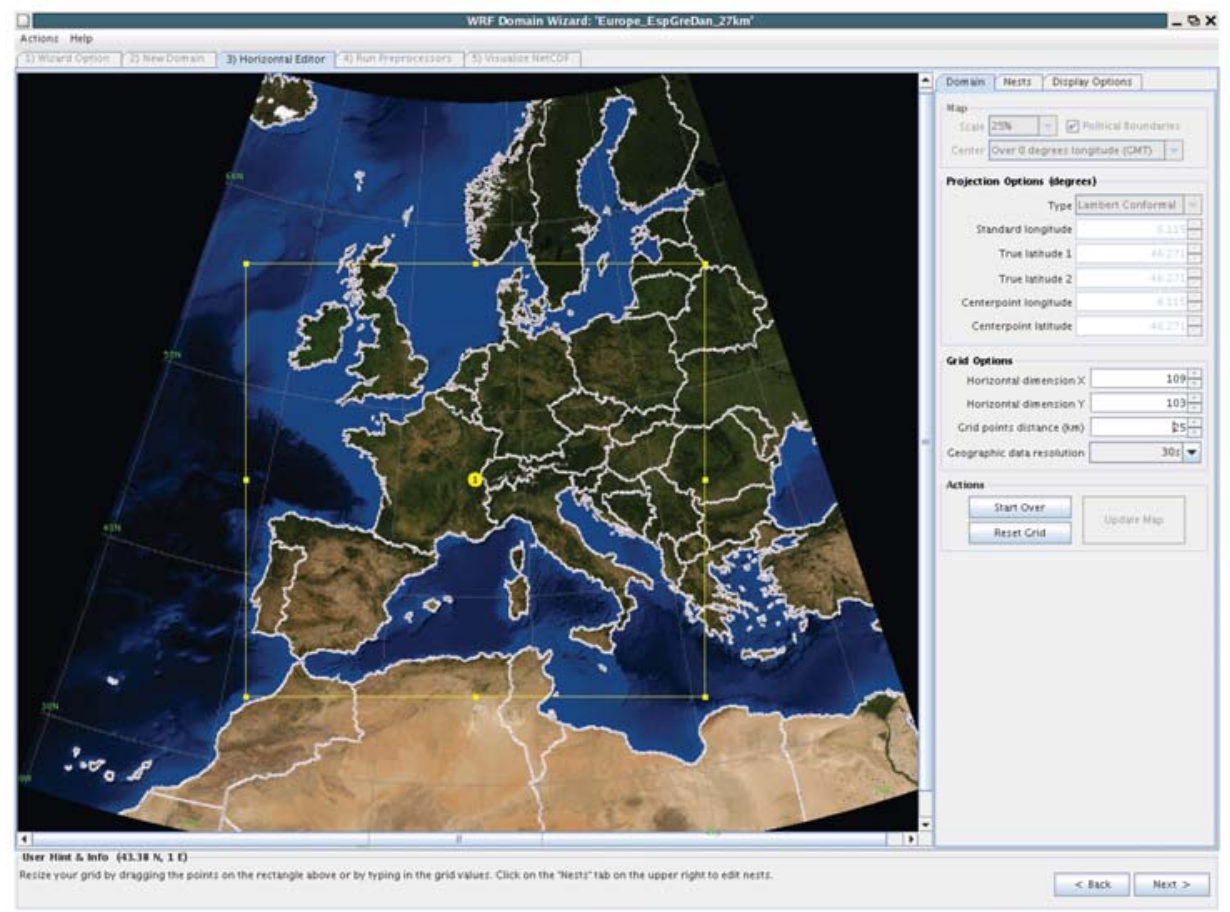

Fig. 1. Geographical coverage of the "FleaTickRisk" bio-meteorological model. 
The model's integration time step for this project is variable due to the activation of the "adaptative time step" option. This option is designed to use the maximum time step meeting the CourantFriedrichs-Levy (CFL) numerical stability criteria and thus reduce computation time.

The temperature at $2 \mathrm{~m}$, the mixing ratio at $2 \mathrm{~m}$ and the vegetation type field (United States Geophysical Survey) are used to calculate the relative humidity at $2 \mathrm{~m}$ and to create maps. The vegetation type field is constant, unlike the temperature and mixing ratio fields, which are based on the WRF forecasts for the daily values run at 12:00 and 18:00 GMT.

The relative humidity at $2 \mathrm{~m}$ is based on the temperature and on the mixing ratio, using Rankine's equation (Laprise, 1992):

$$
\text { In }\left(P_{\text {sat }}\right)=13.7-\frac{5120}{T_{2}}
$$

where $P_{\text {sat }}$ is the saturating vapour pressure in atmospheres and $T_{2}$ is the temperature at $2 \mathrm{~m}$. Given that:

$$
R H=\frac{P_{v a p}}{P_{\text {sat }}} \times 100 \text { and } P_{v a p}=\frac{q_{2} \times p_{0}}{P_{\text {sat }}},
$$

where $P_{\text {vap }}$ is the water vapour pressure, $p_{0}$ the atmospheric pressure and $q_{2}$ the mixing ratio at $2 \mathrm{~m}$ are used to calculate the relative humidity as follows:

$$
R H=\frac{q_{2} \times p_{0}}{\left(q_{2}+0.622\right) \times e \frac{13.7-\frac{5120}{T_{2}}}{2}}
$$

\section{Biological matrices}

The parasitic activity of the arthropods deemed as present in the geographical area is estimated based on their response to the temperature and relative humidity conditions. The prerequisite was to define the meaning of activity.

Where ticks are concerned, activity is meant as their biological capacity to complete their life cycle, i.e. infest hosts (detection and infestation), feed from the host's blood, then moult into the next stage and wait for a new host to come along. The litera- ture provides minimum, maximum and optimum temperatures, all dependent on the level of humidity, for each tick species (FAO, 1984; Estrada-Peña et al., 2004; Pérez-Eid, 2007). Several authors gave an indication of the rate of evolution of several tick species taking into account an average of temperature and humidity during a certain amount of days. The authors took data from the last models developed by Estrada-Peña et al. (2006, 2007) for the three main tick species (reviewed in Gray et al., 2009). We also used specific in vitro studies: Zahler and Gothe (1995) on D. reticulatus; Jacobs et al. (2004) and Silveira et al. (2009) on R. sanguineus.

We completed matrices based on those existing data (Tables 1, 2 and 3). The percentage of activity is scored on a scale from 0 to 100 , where 0 does not necessarily signify death or absence, but rather a diapause. We have considered only three species: I. ricinus, D. reticulatus and $R$. sanguineus.

The matrix gives an "activity index" which corresponds to a period of 7 days with a specific average of temperature and relative humidity.

I. ricinus, known as the "forest tick" or "wood tick", is a three-stage polytropic, exophilic and hygrophilic tick. Larvae and nymphs feed on micromammals (rodents, lagomorphs or even birds), whereas adults prefer wild herbivores and omnivores (deer, wild boar) but are able to infest all mammals. This tick, originating from central Europe, prefers shaded, humid and fresh areas.

D. reticulatus is also a three-stage polytropic, exophilic and hygrophilic tick, but it prefers more open areas compared to I. ricinus. Larvae and nymphs infest all types of mammals, whereas adults show a tropism for dogs and horses. This tick of European origin has a preference for humid areas, such as riverbanks, the sides of paths, parkland and wasteland.

$R$. sanguineus is a three-stage monotropic, endophilic and xerophilic tick of African origin. All the stages show a tropism for dogs, although other mammals may be infested. It prefers houses (kennels, walls, log cabins), heat and dry conditions.

The cat flea (C. felis felis) is an almost permanent parasite in its adult form. Its activity is defined as 
Table 1. Matrix of activity percentage for Ixodes ricinus. Activity index linked after a period of a 7-day average temperature/humidity.

\begin{tabular}{|c|c|c|c|c|c|c|c|c|}
\hline Temperature & $<5^{\circ} \mathrm{C}$ & $5-10^{\circ} \mathrm{C}$ & $10-15^{\circ} \mathrm{C}$ & $15-20^{\circ} \mathrm{C}$ & $20-25^{\circ} \mathrm{C}$ & $25-30^{\circ} \mathrm{C}$ & $30-35^{\circ} \mathrm{C}$ & $>35^{\circ} \mathrm{C}$ \\
\hline \multicolumn{9}{|c|}{ Relative humidity } \\
\hline$<40 \%$ & 0 & 0 & 0 & 0 & 0 & 0 & 0 & 0 \\
\hline $40-50 \%$ & 0 & 0 & 0 & 0 & 0 & 0 & 0 & 0 \\
\hline $50-60 \%$ & 0 & 0 & 10 & 20 & 10 & 0 & 0 & 0 \\
\hline $60-70 \%$ & 0 & 10 & 30 & 40 & 40 & 10 & 0 & 0 \\
\hline $70-80 \%$ & 0 & 40 & 80 & 80 & 60 & 20 & 0 & 0 \\
\hline $80-90 \%$ & 0 & 60 & 100 & 100 & 70 & 50 & 0 & 0 \\
\hline$>90 \%$ & 0 & 80 & 100 & 100 & 80 & 50 & 0 & 0 \\
\hline
\end{tabular}

Based on: FAO, 1984; Pérez-Eid, 2007; Grays et al., 2009.

Table 2. Matrix of activity percentage for Dermacentor reticulatus. Activity index linked after a period of a 7-day average temperature/humidity.

\begin{tabular}{|c|c|c|c|c|c|c|c|c|}
\hline Temperature & $<5^{\circ} \mathrm{C}$ & $5-10^{\circ} \mathrm{C}$ & $10-15^{\circ} \mathrm{C}$ & $15-20^{\circ} \mathrm{C}$ & $20-25^{\circ} \mathrm{C}$ & $25-30^{\circ} \mathrm{C}$ & $30-35^{\circ} \mathrm{C}$ & $>35^{\circ} \mathrm{C}$ \\
\hline \multicolumn{9}{|c|}{ Relative humidity } \\
\hline$<40 \%$ & 0 & 0 & 0 & 0 & 0 & 0 & 0 & 0 \\
\hline $40-50 \%$ & 0 & 0 & 0 & 10 & 10 & 0 & 0 & 0 \\
\hline $50-60 \%$ & 0 & 0 & 10 & 20 & 20 & 10 & 0 & 0 \\
\hline $60-70 \%$ & 0 & 10 & 30 & 40 & 40 & 20 & 0 & 0 \\
\hline $70-80 \%$ & 0 & 10 & 40 & 70 & 50 & 40 & 10 & 0 \\
\hline $80-90 \%$ & 0 & 20 & 60 & 100 & 100 & 60 & 20 & 0 \\
\hline$>90 \%$ & 0 & 20 & 60 & 100 & 100 & 70 & 20 & 0 \\
\hline
\end{tabular}

Based on: FAO, 1984; Zahler and Gothe, 1995a,b; Pérez-Eid, 2007.

Table 3. Matrix of activity percentage for Rhipicephalus sanguineus in outdoor environment. Activity index linked after a period of a 7-day average temperature/humidity.

\begin{tabular}{|c|c|c|c|c|c|c|c|c|}
\hline Temperature & $<10^{\circ} \mathrm{C}$ & $10-15^{\circ} \mathrm{C}$ & $15-20^{\circ} \mathrm{C}$ & $20-24^{\circ} \mathrm{C}$ & $24-30^{\circ} \mathrm{C}$ & $30-35^{\circ} \mathrm{C}$ & $35-40^{\circ} \mathrm{C}$ & $>40^{\circ} \mathrm{C}$ \\
\hline \multicolumn{9}{|c|}{ Relative humidity } \\
\hline$<20 \%$ & 0 & 0 & 0 & 0 & 0 & 0 & 0 & 0 \\
\hline $20-40 \%$ & 0 & 10 & 10 & 30 & 30 & 20 & 0 & 0 \\
\hline $40-50 \%$ & 0 & 10 & 30 & 60 & 80 & 30 & 0 & 0 \\
\hline $50-60 \%$ & 0 & 10 & 30 & 100 & 100 & 40 & 10 & 0 \\
\hline $60-70 \%$ & 0 & 10 & 30 & 100 & 100 & 60 & 10 & 0 \\
\hline $70-80 \%$ & 0 & 10 & 30 & 100 & 100 & 60 & 20 & 0 \\
\hline $80-90 \%$ & 0 & 10 & 30 & 100 & 100 & 80 & 30 & 0 \\
\hline$>90 \%$ & 0 & 10 & 30 & 100 & 100 & 80 & 50 & 0 \\
\hline
\end{tabular}

Based on FAO, 1984; Jacobs et al., 2004; Pérez-Eid, 2007; Silveira et al., 2009.

Note: Rhipicephalus sanguineus is called "endophile" tick, which means living close to dogs and their environment, but this is often an outdoor tick, find on kennel walls, stone walls, dog walking zone, dog parks and bushes. 
the ability to evolve from the egg to the pupal stage containing a new preemerged flea. As with ticks, data in the literature and population dynamics studies were used to create an activity matrix (Table 4) (Krämer and Mencke, 2001; Beugnet et al., 2004). Unlike the dog flea (Ctenocephalides canis) originating from Europe, C. felis is a felid flea originating from Africa. It is not very specific and can infest cats as well as dogs or other mammals. It loves heat.

Data inserted in the matrix are not fixed, and figures in the matrices will surely be modified based on validation surveys, laboratory studies or new publications. It is known that tick from the same species, for example I. ricinus, have several genotypic populations, which show different geographical distribution and various optimal conditions for their development. It was not possible to take this variability into account on a first approach, therefore the I. ricinus matrix is a middle way.

The tables, based on published parasitology data, are double entry abacuses:

Activity $=\mathrm{f}$ (temperature, relative humidity)

\section{Index calculation}

To build maps, we used both the biological activity tables and the meteorological fields generated by the WRF model. The meteorological data are extracted from a downscaling of GFS forecasts for Europe using the WRF model. The resolution of GFS forecasts is $1^{\circ} \times 1^{\circ}(\sim 100 \mathrm{~km}$ at average latitudes). The horizontal resolution of forecasts downscaled by the WRF model is $27 \mathrm{~km}$.

The duration of exposure has an impact as a prolonged period of heat and humidity stimulates the cycle of the parasites and makes them more active. The maps of weeks W and W-1 show the weekly activity, whereas the 12-week map (W-12) shows the cumulative effect. As the activity of the parasites is reduced at night, we use meteorological data corresponding to WRF outputs at 12:00 and 18:00 GMT.

The activity of the parasites also depends on the type of terrain. Three categories are used to weight the value of gross activity: (i) urban and periurban, (ii) forests and "wild" areas, and (iii) fields and parkland. For each cell on the WRF grid (horizontal resolution $=27 \mathrm{~km}$ ), we calculate the percentage of each of these three categories based on the USGS (United States Geophysical Survey) maps with a resolution of $1 \mathrm{~km}^{2}$, so that the sum of all three percentages totals 100 :

$$
\% \text { forests }+\% \text { fields }+\% \text { urbans }=100 \%
$$

These percentages per category are used to calculate an overall weighting coefficient, dependent on the type of parasite (the development of each parasite varies in each of these three categories) (Table 5).

Table 4. Matrix of activity percentage for Ctenocephalides felis felis fleas in an outdoor environment. Activity index linked after a period of a 7-day average temperature/humidity.

\begin{tabular}{|c|c|c|c|c|c|c|c|}
\hline Temperature & $<10^{\circ} \mathrm{C}$ & $10-15^{\circ} \mathrm{C}$ & $15-20^{\circ} \mathrm{C}$ & $20-25^{\circ} \mathrm{C}$ & $25-30^{\circ} \mathrm{C}$ & $30-35^{\circ} \mathrm{C}$ & $>35^{\circ} \mathrm{C}$ \\
\hline \multicolumn{8}{|c|}{ Relative humidity } \\
\hline$<40 \%$ & 0 & 0 & 0 & 0 & 0 & 0 & 0 \\
\hline $40-50 \%$ & 0 & 0 & 0 & 10 & 10 & 0 & 0 \\
\hline $50-60 \%$ & 0 & 0 & 10 & 20 & 20 & 10 & 0 \\
\hline $60-70 \%$ & 0 & 0 & 30 & 40 & 40 & 20 & 0 \\
\hline $70-80 \%$ & 0 & 0 & 30 & 100 & 80 & 30 & 0 \\
\hline $80-90 \%$ & 0 & 0 & 40 & 100 & 100 & 50 & 10 \\
\hline$>90 \%$ & 0 & 0 & 40 & 100 & 100 & 60 & 10 \\
\hline
\end{tabular}

Note: the model shows the capacity of fleas to multiply and live outdoors. It does not take into account their indoor environment (houses and flats). Consequently, the absence of activity in winter is applicable only to gardens, bushes, and unheated outbuildings, whereas the lifecycles of fleas never stops in heated environments (even though it slows down at the usual temperature settings of $19-22^{\circ} \mathrm{C}$ ). 
Table 5. Moderator coefficients.

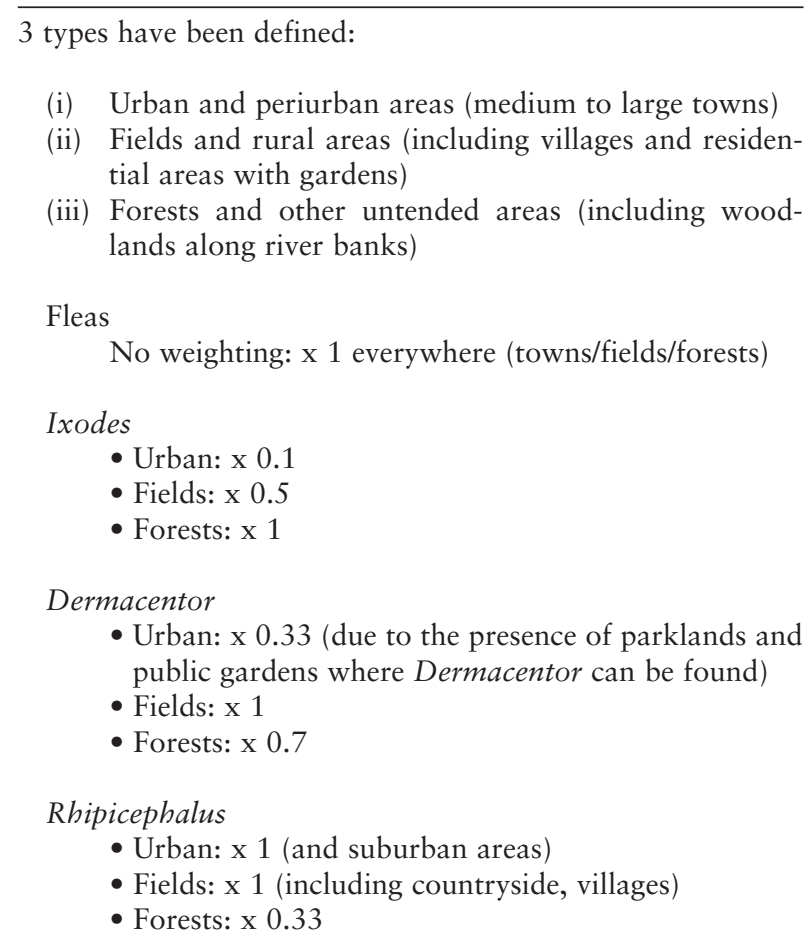

The purpose of those coefficients is not to calculate a suitability index but just to moderate the meteorological index based on coverage of the $27 \mathrm{~km}^{2}$.

Example: calculation of the weight of vegetation for Ixodes; urban: 0.333 , field: 0.8 , forest: 1.0 .

For a geographical cell including 5\% town, $80 \%$ field, and $15 \%$ forest, the weighting coefficient is:

weight_coefficient $=0.333 \times 0.05+0.8 \times 0.8+1.0$ x $0.15=0.80665$

The coefficient is applied for each arthropod species and each pixel of $27 \mathrm{~km}^{2}$. It is just a moderator used for the meteorological activity index but it is not at all a suitability index. As already explained the activity index is given for ticks in a suitable biotope. Those biotopes are not seen on the maps. The authors are pursuing complementary research on this topic which could be added in the future to the weather model.
As the meteorological data are WRF outputs which are only forecasts, later corrected by real data, there are no true observations for the previous week. Therefore, we use all the forecasts at 1 day from the previous week to build a "pseudo-observation". The forecast at 1 day being of excellent quality, the error attached to this approximation is very small. In practice, the quality of the forecast data at $\mathrm{D}+1$ is superior in terms of homogeneity, availability, precision and geographical distribution than the majority of the observation data in Europe.

To calculate the biological activity of the previous week (W-1), we use the following equation:

$W-1=$ Average $_{b \in S^{-}}-1$ abacus $\left(\mathrm{T}_{b}, \mathrm{RH}_{b}\right) \times$ Weight $_{\text {vegetation }}$

where $\mathrm{h}$ is the hours of week W-1 used for the calculation ( $\mathrm{h}=12: 00$ and 18:00 GMT).

For the coming week (W), the calculation is similar, except that it is based on the forecast for Monday morning.

$W=$ Average $_{b \in S}-1$ abacus $\left(\mathrm{T}_{b}, \mathrm{RH}_{b}\right) \times$ Weight $_{\text {vegetation }}$

The calculation of the cumulated activity is slightly more complex as it takes into account the exponential nature of the growth, associated with the development and multiplication of the parasites over a long period. The weekly contributions are multiplied.

If $\mathrm{Wi}$ is the estimated activity for Week $\mathrm{i}$, the following equation is used for the cumulated activity:

$$
\begin{gathered}
W_{-12}=\mathrm{K} \times \log \left(W_{1} x W_{2} x W_{3} x W_{4} x W_{5} x W_{6} x\right. \\
\left.x \frac{W_{7}}{2} \times \frac{W_{8}}{3} \times \frac{W_{9}}{4} \times \frac{W_{10}}{5} \times \frac{W_{11}}{6} \times \frac{W_{12}}{7}\right)
\end{gathered}
$$

Factor $K$ is used to maintain the logarithmic scale in a window ranging from 0 to 1,000 .

Each week, we obtain three indexes centred on each $27 \mathrm{~km}^{2}$ cell covering the extension area. This gross result is very difficult to interpret, hence the decision to create maps representing levels of indexes. 


\section{Creation of maps}

From January 2007 to September 2008, we worked solely on France to validate the model. Since October 1st, 2008, we have been calculating each week (on Monday mornings) the activity maps of four parasites, i.e. fleas, Rhipicephalus, Ixodes and Dermacentor, for the whole geographical area. For each parasite, three types of maps were created:

(i) activity during the previous week (week W-1);

(ii) expected activity for the coming week (week W); and

(iii) cumulated activity over the previous 12 weeks (W-12).

These 12 maps were created for the geographical area lying between longitudes $10.5^{\circ} \mathrm{W}$ and $30^{\circ} \mathrm{E}$ and latitudes $37.75^{\circ} \mathrm{N}$ and $62^{\circ} \mathrm{N}$, with a horizontal resolution of $27 \mathrm{~km}$ (Fig. 1). For visualisation purposes, each of the 12 maps created for Europe is subdivided into 40 maps using the geographical resolution of a country or a region, according to the list given in Table 6.

To improve clarity, the activity indexes are grouped within an interval to which we have given a colour.

The intervals chosen for the weekly activity (W and W-1) are: [0;15]; [15;40]; [40;65] and [65;100]. The intervals chosen for the cumulated activity (W12) are: [0;200]; [200;400]; [400;600]; [600;800] and $[800 ; 1000]$.

The maps are generated based on isoclines of the indexes per pixels using specific mapping software.

For the weekly activity, colours range from yellow, light orange, dark orange to red, signalling an increasing parasitic activity. Therefore, the risk of infestation is maximum for a dog or a cat in an area where ticks are present as the latter have been "activated" by the climate. The cumulated activity over 12 weeks is expressed as a weighted geometric average, whose weight decreases as of week -7. This value is used to determine whether the given parasite has had a favourable climate; a fair climate, i.e. sometimes good sometimes bad; or an unfavourable climate over a prolonged period. Obviously, if the parasites have had a favourable climate for at least
Table 6. Sub-divisions in the maps of the FleaTickRisk model.

\begin{tabular}{|c|c|c|}
\hline \multicolumn{3}{|c|}{ Europe } \\
\hline & \multicolumn{2}{|l|}{ Balkans } \\
\hline & & Balkans_North \\
\hline & & Balkans_South \\
\hline & \multicolumn{2}{|l|}{ Bulgaria } \\
\hline & \multicolumn{2}{|l|}{ Czech Rep } \\
\hline & \multicolumn{2}{|l|}{ Denmark } \\
\hline & \multicolumn{2}{|l|}{ France } \\
\hline & & France_North_East \\
\hline & & France_North_West \\
\hline & & France_South_East \\
\hline & & France_South_West \\
\hline & \multicolumn{2}{|l|}{ Germany } \\
\hline & & Germany_North_East \\
\hline & & Germany_North_West \\
\hline & & Germany_South_East \\
\hline & & Germany_South_West \\
\hline & \multicolumn{2}{|l|}{ Greece } \\
\hline & \multicolumn{2}{|l|}{ Hungary } \\
\hline & \multicolumn{2}{|l|}{ Ireland } \\
\hline & \multicolumn{2}{|l|}{ Italy } \\
\hline & & Italy_North \\
\hline & \multirow{2}{*}{\multicolumn{2}{|c|}{ Latvia_Lithuania_Estonia }} \\
\hline & & \\
\hline & \multicolumn{2}{|l|}{ Netherlands_Belgium } \\
\hline & \multicolumn{2}{|l|}{ NorthLands (Scandinavia) } \\
\hline & \multicolumn{2}{|l|}{ Poland } \\
\hline & & Poland_East \\
\hline & & Poland_West \\
\hline & \multicolumn{2}{|l|}{ Romania } \\
\hline & \multicolumn{2}{|l|}{ Scandinavia } \\
\hline & \multicolumn{2}{|l|}{ Slovakia } \\
\hline & \multicolumn{2}{|l|}{ Slovenia } \\
\hline & \multicolumn{2}{|l|}{ Spain } \\
\hline & & Spain_North \\
\hline & & Spain_South \\
\hline & \multicolumn{2}{|l|}{ Switzerland } \\
\hline & & UK_North \\
\hline & & UK_South \\
\hline
\end{tabular}

3 months, their numbers will be high. Therefore, this index reflects the density of the parasite populations. To help the reading, a colour-coded scale is used, ranging from green, to beige, light brown, brown and dark brown (from the less favourable to the most favourable).

We compared the results provided by the maps for the years 2007-2008 with the geographical distribution and prevalence of tick species and fleas provid- 
ed by epidemiological surveys, first in France for ticks (Beugnet et al., 2003; Clément-Sailhac, 2003; Savary, 2003; Halos et al., 2005; Vayssier-Taussat et al., 2005; Marotel, 2006), then in the UK, Germany, Spain, Italy and Hungary for fleas (Bond et al., 2005; Beck et al., 2006; Rinaldi et al., 2007; Gracia et al., 2008; Farkas et al., 2009). The activity areas for the species examined matched the published geographical distribution maps.

\section{Results and Discussion}

It is essential to interpret the data generated by the FleaTickRisk model. The robustness and reliability of the climatic WRF model are recognised worldwide and are used by numerous scientists and researchers in climatology and oceanography. The interpretation of the results must be based on the parasitology data. The biological matrices were created using published data, but they could be changed and/or refined according to more recent results, particularly field validation surveys resulting from on-going tick collections in France, Belgium, Hungary, Germany and the UK. Using statistical series combining tick counts and series of the indexes provided by the model in several biotopes all over Europe, we will be able to adapt and improve the model continuously.

A 1-year survey was conducted in France from mid-2008 to mid-2009 in collaboration with the veterinary services from the French Army. Fifteen sites were selected for tick collections. The methodology was rigorously followed and ticks were collected in nine out of the 15 sites (Fig. 6). The ticks were collected by flagging every 2 weeks using the same methodology (flags of $1 \mathrm{~m}^{2}$, distance of $500 \mathrm{~m}$ in length) which is described for Ixodes ticks. The ticks were counted and identified.

I. ricinus ticks were abundant only in five sites whereas other tick species were also found: $R$. sanguineus, D. reticulatus and D. marginatus, Haemaphysalis punctata and Ixodes hexagonus.

Even by trying to be as rigorous as possible, it is known that tick collection is highly variable, with

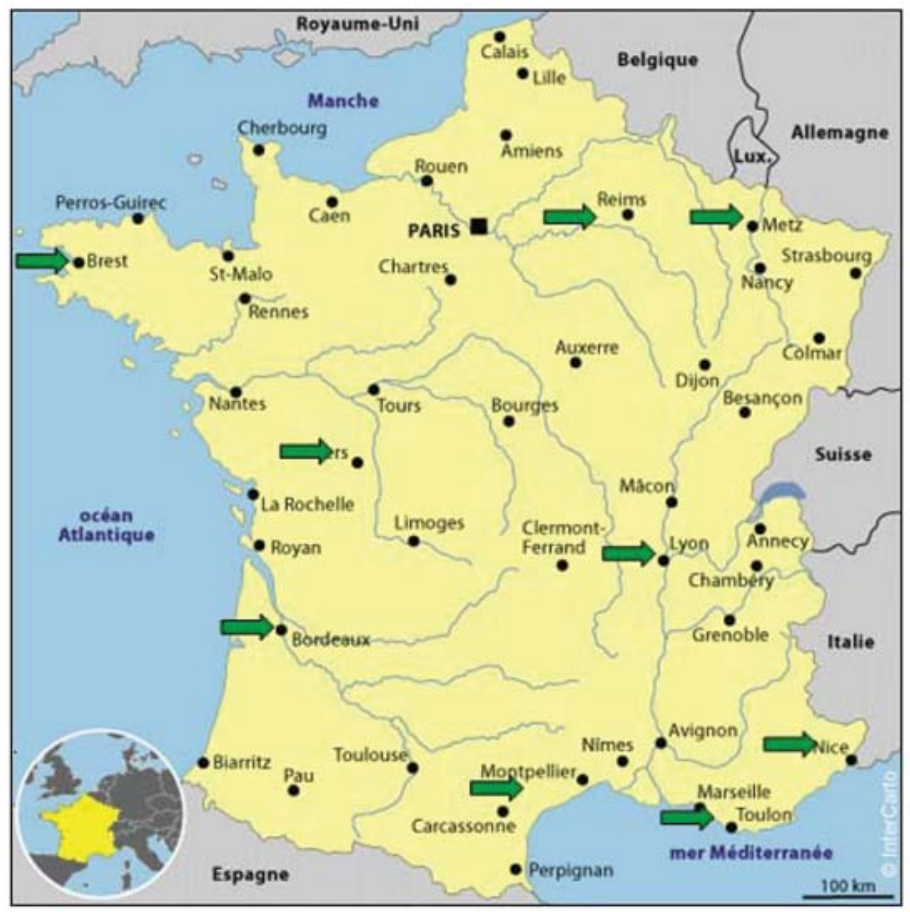

Fig. 6. French locations of the 2008-2009 tick survey (green arrows). 
highly aggregative distribution of the ticks. We took only into account the adults and nymphs. The counting is also variable depending on the timing (collects were done between 10:00 and 16:00 hours) and the daily weather (especially under raining conditions).

Despite this very high variability, we compared the activity (AI) and cumulative (CI) indexes and the tick counts for I. ricinus (Tables 7, 8 and 9). The indexes were calculated using the GPS location of the collections.

When the indexes were very low, always below 10 for the AI and 100 for the CI, there were no Ixodes found (locations in South of France) or very few (less than 22) in the case of the South-West site (Bordeaux), located in a pine forest (Table 9).

For the North-West sites (Brest and Rennes) with an Oceanic climate, the indexes appeared too low compared to the tick counts. The climate is quite stable in those areas with strong humidity and never very low or high temperatures.

For the Central and Eastern locations, the graphics are showing a good fit between tick counts and indexes. We did non parametric Spearman's rank correlation rho tests which showed a significant correlation between the indexes and the tick counts (Table 10). A difference in the timing of the cumulative index decrease and the tick count decrease was seen. It is directly related to the mode of calculation of the cumulative index, which takes into account the past weeks (which were still favourable). This mode of calculation induces a delay which will have to be corrected.

Those comparisons between the indexes and the tick collections will be done also with the collections that are ongoing in other countries (Belgium, The Netherlands and UK). In a subsequent step, we will adapt and modify the biological matrix in order to improve the correlations and to verify that they are accurate for all geographical locations.

We probably have to put in place a specific methodology, including tick counts on animals, for Dermacentor and Rhipicephalus.

The analysis of the biotope is not precise in this essentially meteorological model. Only three levels
Table 7. Comparison between the 1-year tick collections throughout France and the AI for Ixodes ricinus ticks. Day 0 is the 15th of March. The index number is seen on the left. The dots corresponding to the tick numbers are calculated as follows: $15 * \log$ (nymph + adult tick number).
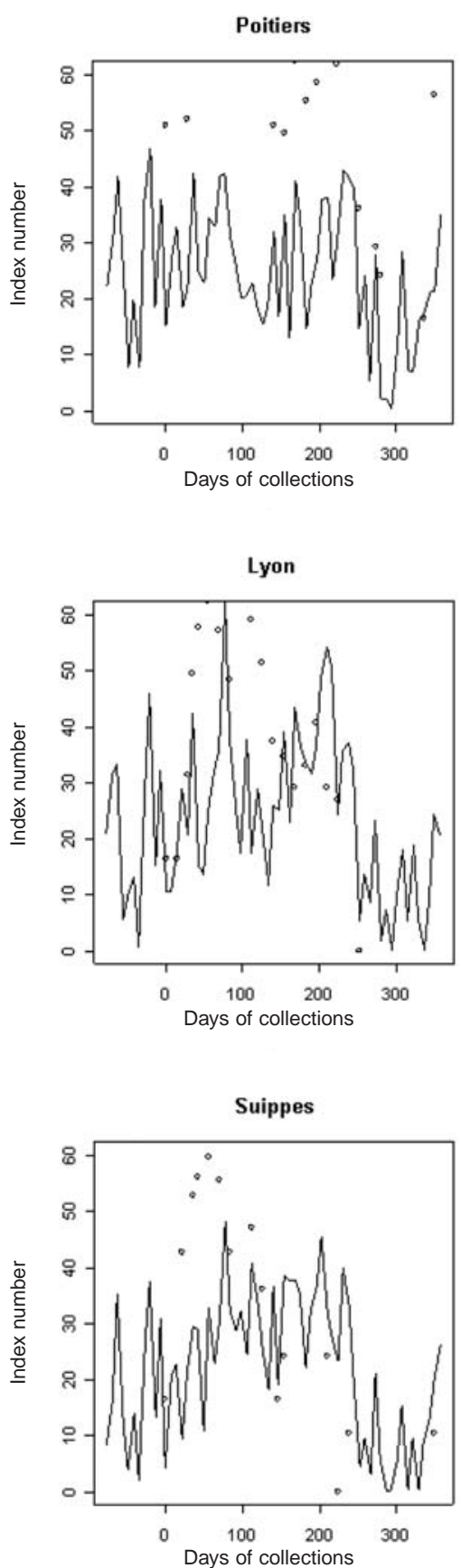
Table 8. Comparison between the 1-year tick collections throughout France and the CI for Ixodes ricinus ticks. Day 0 is the $15^{\text {th }}$ of March. The index number is seen on the left. The dots corresponding to the tick numbers are calculated as follows: $2.5 * \log$ (nymph + adult tick number).

Brest

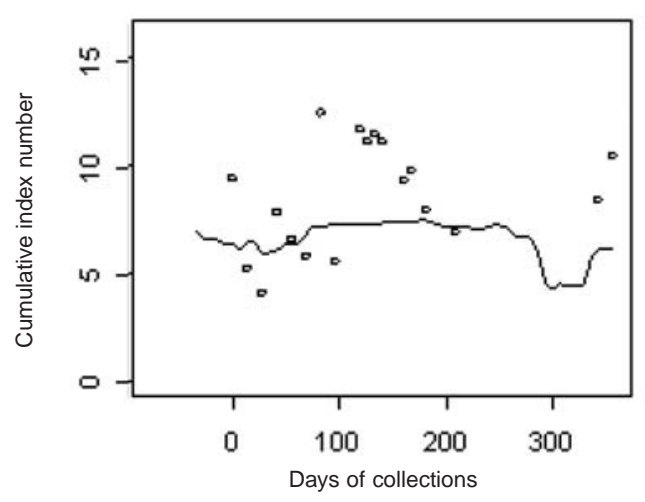

Poitiers

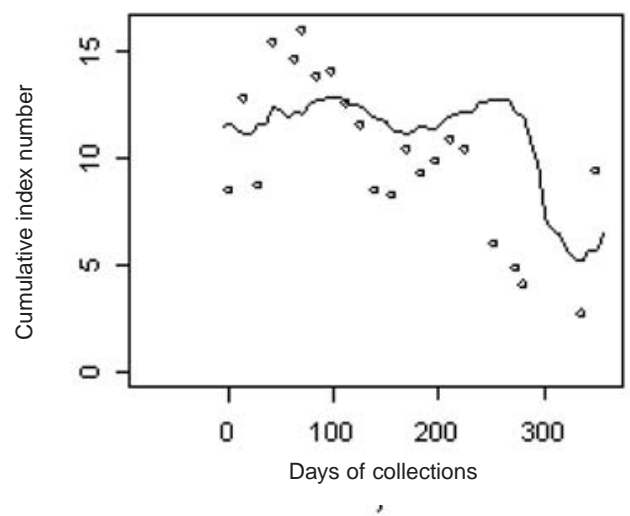

have been defined. We are working to improve this aspect by integrating a fine, multilayered cartographic analysis of the biotopes favourable to the ectoparasites (Koch et al., 2007). At this time, the model gives only the ability for one tick species to do its life cycle where the biotope is adapted. This condition needs to be known by local people, for example the veterinarian practitioners knowing the "tick zones" in their area.

Given the abundance of wildlife (rodents, deer, wild boars, foxes), domestic animals (ruminants, horses) and cats and dogs in Europe, we decided that host populations are not a limiting factor for the tick and flea populations. This notion will have
Rennes

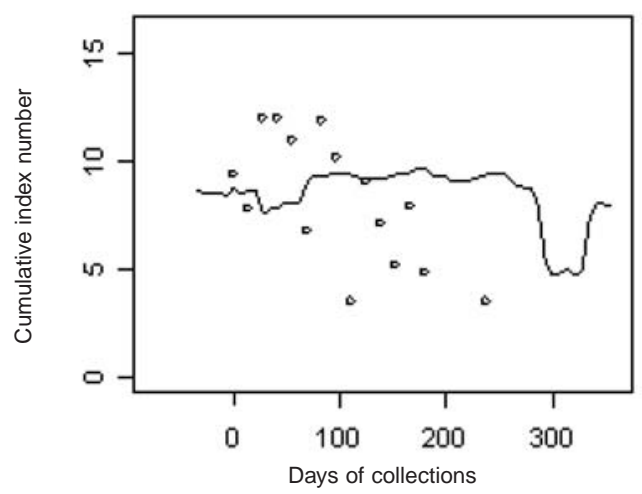

Lyon

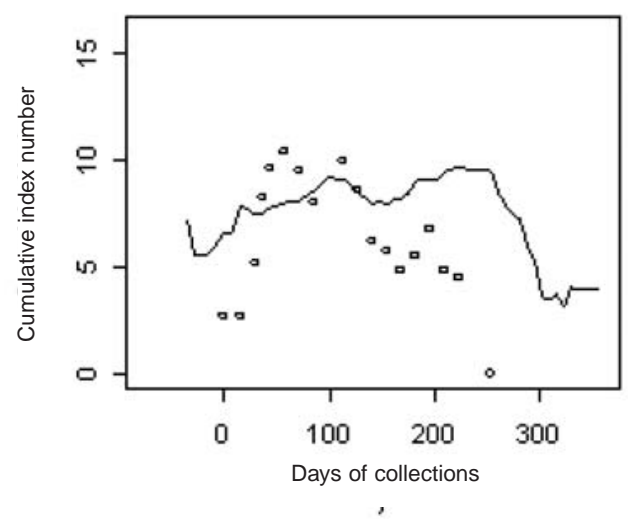

to be improved in the future, along with a precise analysis of the biotopes, especially for R. sanguineus and D. reticulatus.

For the time being, the FleaTickRisk model is mainly bio-meteorological, taking into account mostly the temperature and humidity. The wind as such has not been integrated as we are only considering arthropods living on the ground, and not flying diptera such as mosquitoes, Phlebotomus or Culicoides. The activity associated with climatic conditions is a criteria for the risk of infestation, assuming the parasite is present. If there is a risk of infestation, there is therefore a risk of transmission of vector-borne diseases by the given arthropod. 
Table 9. AI for Ixodes ticks in South West. Day 0 is the $15^{\text {th }}$ of March. The index number is seen on the left.

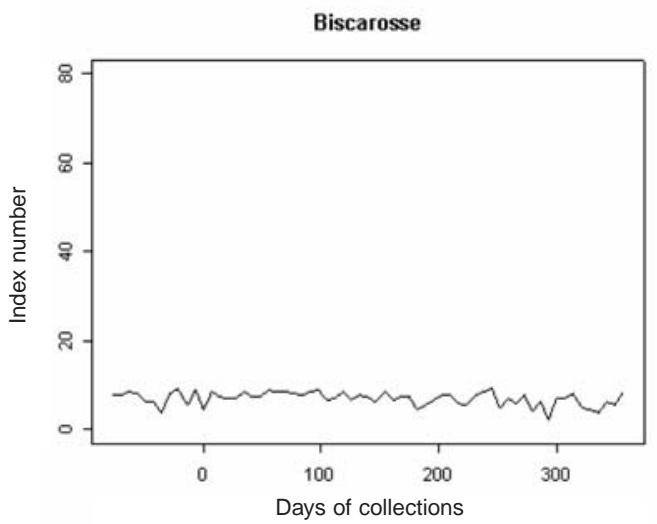

Table 10. Non parametric Spearman's rank correlation (rho) between tick counts and indexes.

\begin{tabular}{llcc}
\hline Location & Index & rho & P-value \\
\hline Suippes & Activity & 0.482 & 0.017 \\
& Cumulative & 0.294 & 0.160 \\
Poitiers & Activity & 0.450 & 0.036 \\
& Cumulative & 0.431 & 0.045 \\
Lyon & Activity & 0.427 & 0.033 \\
& Cumulative & 0.397 & 0.049 \\
\hline
\end{tabular}

Within the same geographical area, the three maps must be observed and compared.

The AI of the previous week is a criteria for the risk of infestation and transmission of pathogens, mainly Babesia, Ehrlichia, Anaplasma, Rickettsia, or even tick-borne encephalitis virus, present in Europe (Azad et al., 1997; Klimes et al., 2001; Bermann et al., 2002; Leschnick et al., 2002; Bown et al., 2003; Rolain et al., 2003; Shaw et al., 2004; Parola et al., 2005; Bourdoiseau, 2006; Kowalski et al., 2006; Oteo et al., 2006). This map will therefore provide veterinarians with epidemiological facts, which may lead them to suspect certain diseases.

The risk of infestation is evaluated using the map forecasting the activity for the coming week. This map provides indications regarding any host animal present in the area examined, or expected to arrive in the area (e.g. pets travelling with their owners on holiday). However, this risk must be amended by the map of cumulated activity over 12 weeks. There are several possible cases.

Case \#1: the expected level of activity is unfavourable on the weekly map, and also low on the map of cumulated activity: the risk is probably low. This situation is typical of the winter season.

Case \#2: the expected level of activity is favourable on the weekly map, but it is low on the map of cumulated activity: the parasites are active but their numbers are likely to be low as the climatic conditions were poor during the previous weeks. This situation is typical of the end of winter and beginning of spring.

Case \#3: the expected level of activity is favourable on the weekly map, as well as on the map of cumulated activity: the parasites are active and their numbers are likely to be high as climatic conditions have been good for several weeks. This situation is typical of summer.

Case \#4: the expected level of activity is unfavourable on the weekly map, but it is good on the map of cumulated activity: the parasites are not very active, but their numbers are likely to be high as climatic conditions have been good for several weeks. This situation is typical of autumn.

Besides these general trends, variations are seen depending on the parasites, as the reactive side of the model depends on the biological requirements of the arthropod. Therefore, Ixodes and Dermacentor are active in Northern Europe, including in winter, whereas Rhipicephalus is more active in summer and in the South.

When climatic conditions are unfavourable (too cold, too hot or too dry), parasite populations drop in numbers but not all parasites are destroyed, as the majority of ticks enter diapause. For fleas, there is always a reservoir of cocoons in houses, which will boost the numbers as soon as conditions become favourable again.

The data supplied by the model must be considered as an epidemiological tool available to veterinarians and to other healthcare professionals to improve the advice given to animal owners. The model is an example of imaging used as a predictive 


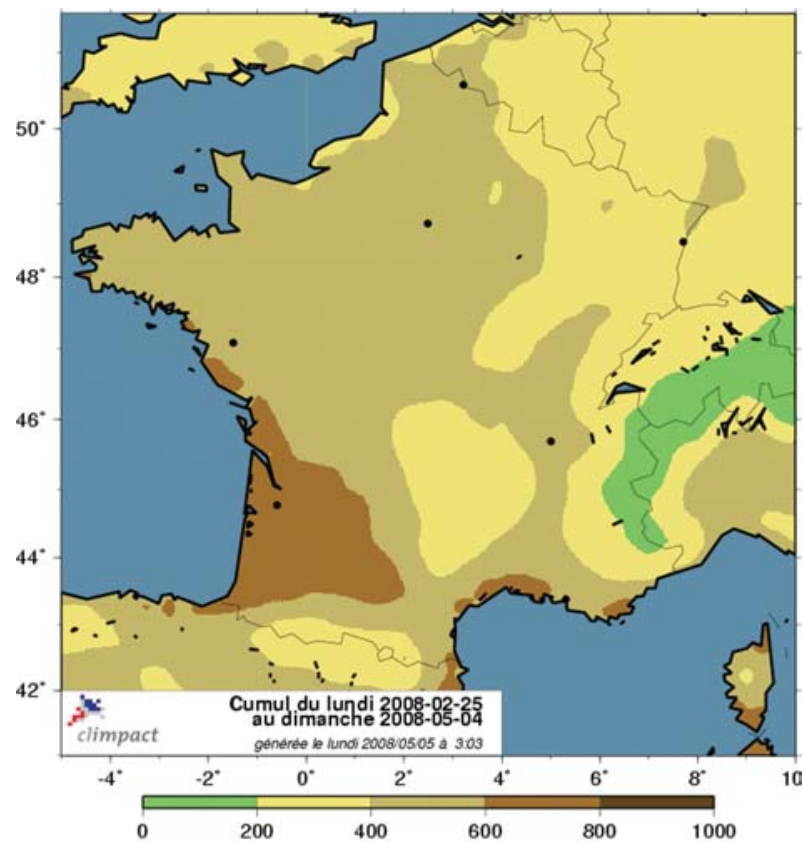

Cumulative activity index for Ixodes and Dermacentor (from the 25/02/2008 to the $04 / 05 / 2008$ )

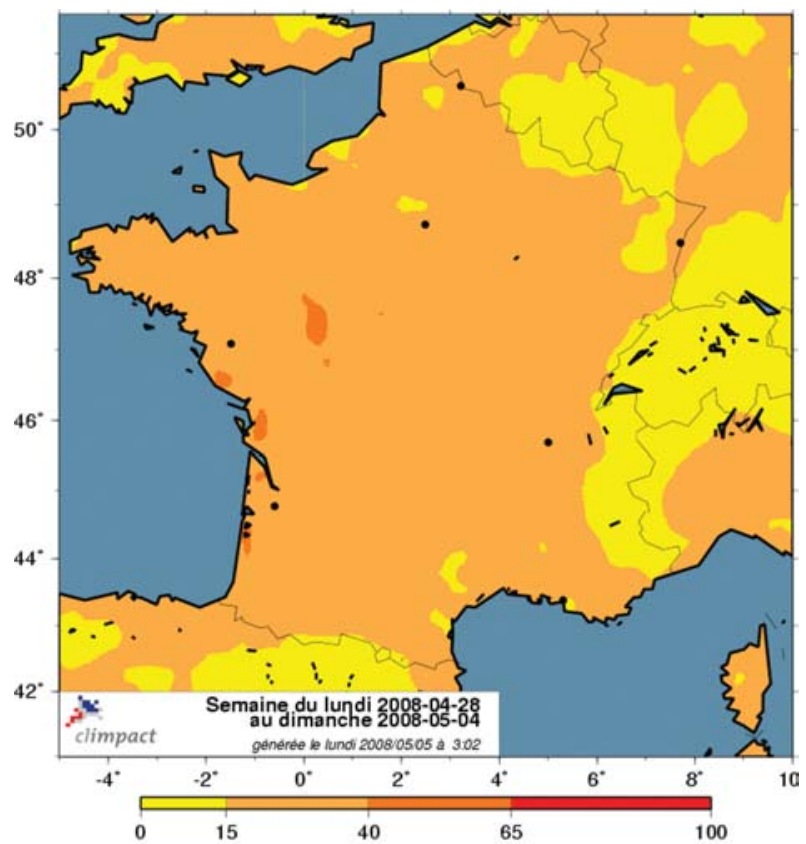

Activity index for Ixodes and Dermacentor (week from the 28/04/2008 to the 04/05/2008)

Fig. 2. Examples of weekly and cumulated activity maps during the spring of 2008 for Ixodes and Dermacentor.

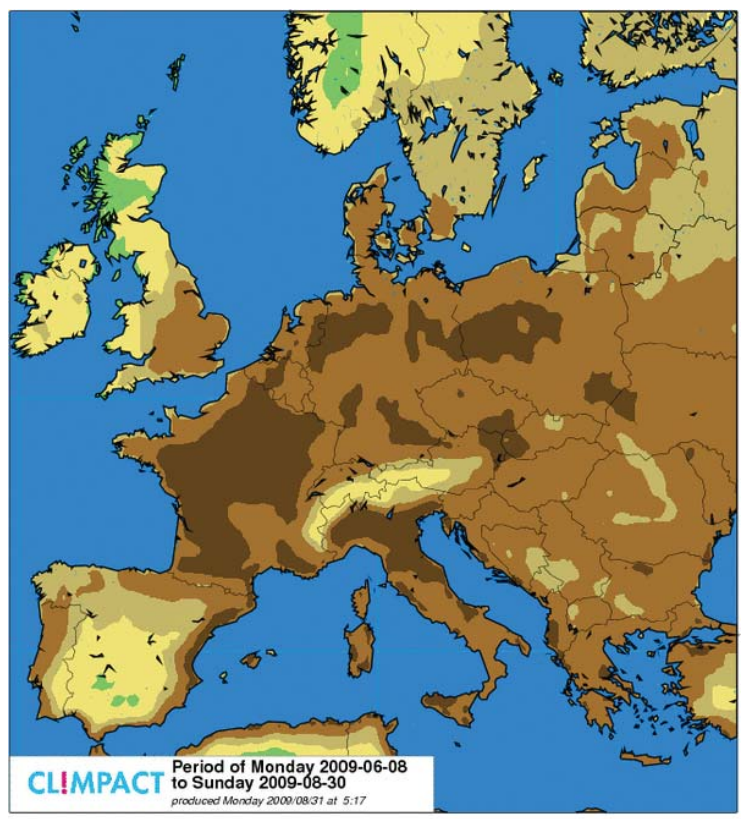

\begin{tabular}{llllll}
\hline 0 & 200 & 400 & 600 & 800 & 1000
\end{tabular}

Cumulative activity index for Rhipicephalus (from the $23 / 06 / 2008$ to the $31 / 08 / 2008$ )
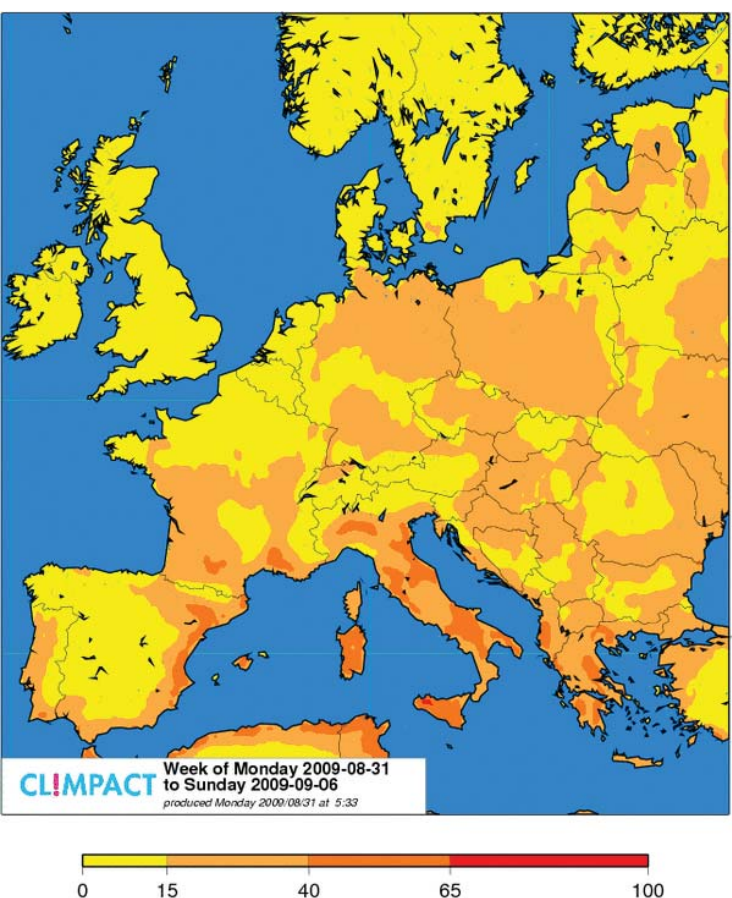

Fig. 3. Examples of weekly and cumulated activity maps during the summer of 2008 for Rhipicephalus. 


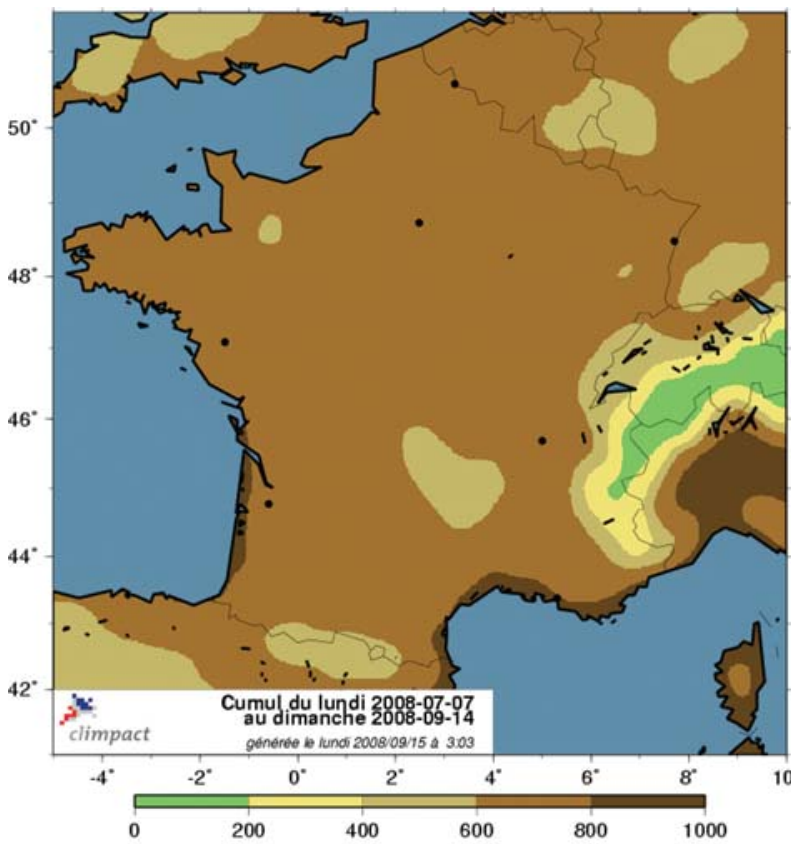

Cumulative activity index for Ctenocephalides (from the $07 / 07 / 2008$ to the $14 / 09 / 2008$ )

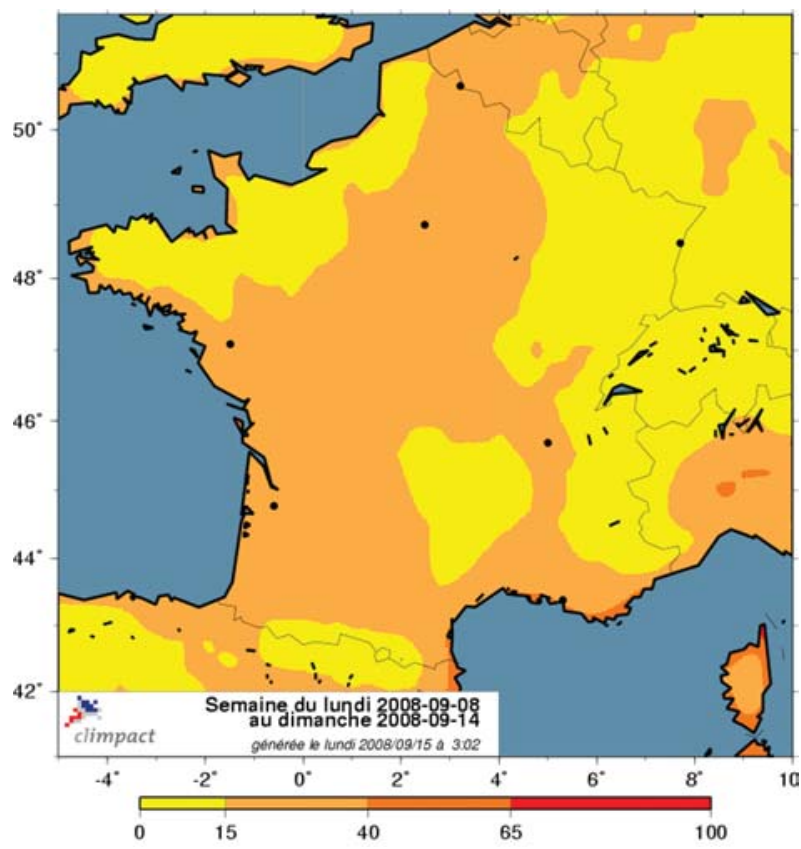

Activity index for Ctenocephalides (week from the 08/09/2008 to the 14/09/2008)

Fig. 4. Examples of weekly and cumulated activity maps during the autumn of 2008 for Ctenocephalides.

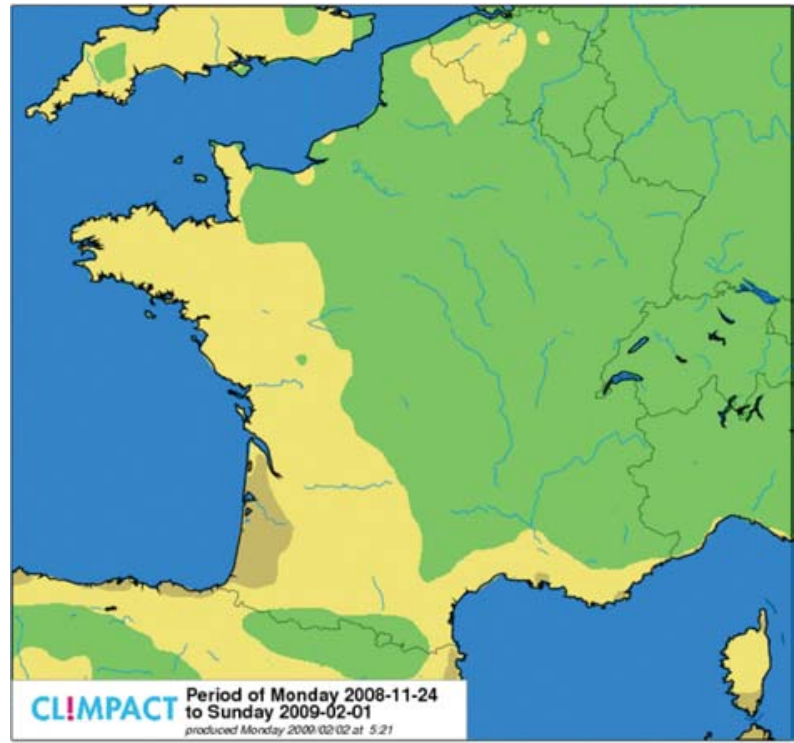

200

400

600

800

Cumulative activity index for Ixodes and Dermacentor (from the 24/11/2008 to the 01/02/2009)

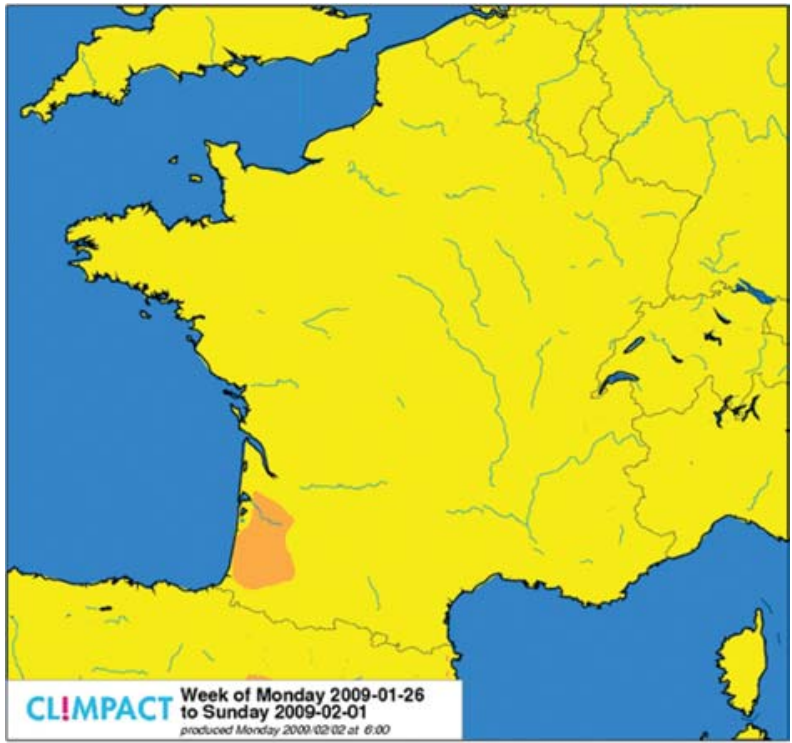

65

100

Activity index for Ixodes and Dermacentor (week from the 26/01/2009 to the 01/02/2009)

Fig. 5. Examples of weekly and cumulated activity maps during the winter of 2008 for Ixodes and Dermacentor. 
tool, in this instance meteorology, for epidemiological purposes (Martin et al., 2007).

The model may also be used on a given geographical area, up to 50 years back or over a future period, based on forecast climatic changes, to demonstrate the impact of the climate on the geographical distribution of a particular species. For example, it is possible to examine the climatic limit of the localisation and the activity of $R$. sanguineus over a prolonged period, and to demonstrate that this species may, from now on, establish itself in the Northern half of France, in Belgium or in Germany (on-going study).

\section{References}

Anthes RA, Warner TT, 1978. Development of hydrodynamic models suitable for air pollution and other mesometeorological studies. Mon Wea Rev 106, 1045-1078.

Azad AF, Radulovic S, Higgins JA, Noden BH, Troyer JM, 1997. Flea-borne rickettsioses: ecologic considerations. Emerg Infect Dis 3, 319-327.

Beck W, Boch K, Mackensen H, Wiegand B, Pfister K, 2006. Qualitative and quantitative observations of the flea population dynamics of dogs and cats in several areas in Germany. Vet Parasitol 137, 130-136.

Bermann F, Davoust B, Fournier PE, Brisou-Lapointe AV, Brouqui P, 2002. Ehrlichia equi (Anaplasma phagocytophila) infection in an adult horse in France. Vet Rec 150, 787-788.

Beugnet F, Chalvet-Monfray K, Sabatier P, 1998. Use of a mathematical model to study the control measures of the cattle tick Boophilus microplus population in New Caledonia. Vet Parasitol 77, 277-288.

Beugnet F, Kenny MJ, Day MJ, Shaw SE, 2003. A PCR-based comparative survey of arthropod-transmitted infections in dogs, cats and prevalence in ticks in southern France. Proceedings of the Congress of WAAVP 2003, New Orleans, USA.

Beugnet F, Loukos H, Chalvet-Monfray K, Bicout D, 2008. FleaTickRisk: a climatic model developed to monitor and predict the activity and the density of 3 tick species and the cat flea in France. Proceedings the Congress EMOP X, Paris, France.

Beugnet F, Porphyre T, Sabatier P, Chalvet-Monfray K, 2004.
Use of a mathematical model to study the dynamics of Ctenocephalides felis populations in the home environment and the impact of various control measures. Parasite 11, 387-399.

Bond R, Riddle A, Mottram L, Beugnet F, Stevenson R, 2007. Survey of flea infestation of dogs and cats in the United Kingdom during 2005. Vet Rec 160, 503-506.

Bourdoiseau G, 2006. Canine babesiosis in France. Vet Parasitol 138, 118-125.

Bown KJ, Begon M, Bennett M, Woldehiwet Z, Ogden NH, 2003. Seasonal dynamics of Anaplasma phagocytophila in a rodent-tick (Ixodes trianguliceps) system, United Kingdom. Emerg Infect Dis 9, 63-70.

Clément-Sailhac ML, 2003. Maladies transmises par les tiques dans le Sud de la France chez les carnivores domestiques. Th.Doc.Vét. Lyon, N¹10, Octobre 2003, 80 pp.

Estrada-Peña A, 2008. Climate, niche, ticks, and models: what they are and how we should interpret them. Parasitol Res 103, S87-S95.

Estrada-Peña A, Bouattour A, Camicas JL, Walker AR, 2004. Ticks of domestic animals in the Mediterranean region. International Consortium on Ticks and Tick-Borne Diseases (ICTTD-2), Ed. University of Zaragoza, Spain, ISBN 8496214-18-4, 2004, $131 \mathrm{pp}$.

Estrada-Peña A, Horak IG, Petney T, 2008. Climate changes and suitability for the ticks Amblyomma hebraeum and Amblyomma variegatum (Ixodidae) in Zimbabwe (19741999). Vet Parasitol 151, 256-257.

Estrada-Peña A, Venzal JM, 2007. A GIS framework for the assessment of tick impact on human health in a changing climate. Geospat Health 2, 157-168.

FAO, 1984. Ticks and tick-borne disease control. A practical field manual. Vol 1. Ed FAO, Rome, 299 pp.

Farkas R, Gyurkovsky M, Solymosi N, Beugnet F, 2009. Studies on flea infestation of dogs and cats combined with a questionnaire survey in Hungary. Med Vet Entomol 23, 187-194.

Gracia MJ, Calvete C, Estrada R, Castillo JA, Peribanez MA, Lucientes L, 2008. Fleas parasitizing domestic dogs in Spain. Vet Parasitol 151, 312-319.

Gray JS, Dautel H, Estrada-Pena A, Kahl O, Lindgren E, 2009. Effects of climate change on ticks and tick-borne diseases in Europe. Interdiscip Perspect Infect Dis 593232, 12 pp.

Halos L, Jamal T, Maillard R, Beugnet F, LeMenach A, 
Boulouis A, Vayssier-Taussat M, 2005. Evidence of Bartonella sp. in questing adult and nymphal Ixodes ricinus ticks from France and co-infection with Borrelia burgdorfe$r i$ sensu lato and Babesia sp. Vet Res 36, 79-87.

Klimes J, Juricova Z, Literak I, Schanilec P, Trachta Silva E, 2001. Prevalence of antibodies to tick-borne encephalitis and West Nile flaviviruses and the clinical signs of tickborne encephalitis in dogs in the Czech Republic. Vet Rec 148, 17-20.

Koch DE, Mohler RL, Goodin DG, 2007. Stratifying land use/land cover for spatial analysis of disease ecology and risk: an example using object-based classification techniques. Geospat Health 2, 15-28.

Kowalski J, Hopfenmüller W, Fingerle V, Malberg H, Eisenblätter M, Wagner J, Miksits K, Hahn H, Ignatius R, 2006. Seroprevalence of human granulocytic anaplasmosis in Berlin/Brandenburg, Germany: an 8-year survey. Clin Microbiol Infect 12, 924-927.

Krämer F, Mencke N, 2001. Flea Biology and Control. Ed Springer, ISBN 3-540-41776-1, 192 pp.

Jacobs PA, Fourie L, Horak IG, 2004. A laboratory comparison of the life cycles of the dog ticks Haemaphysalis leachi and Rhipicephalus sanguineus. Onderstepoort J Vet Res 71, 15-28.

Laprise R, 1992. The Euler equations of motion with hydrostatic pressure as an independent variable. Mon Wea Rev 120, 197-207.

Leschnik MW, Kirtz GC, Thalhammer JG, 2002. Tick-borne encephalitis (TBE) in dogs. Int J Med Microbiol 291, 66-69.

Lindgren E, Gustafson R, 2001. Tick-borne encephalitis in Sweden and climate change. Lancet 358, 16-18.

Marechal F, Ribeiro N, Lafaye M, Güell A, 2008. Satellite imaging and vector borne diseases: the approach of the French National Space Agency (CNES). Geospat Health 3, 1-5.

Marhrenholz P, 2008. Climate changes and adaptation needs. Parasitol Res 103, 139-146.

Marotel M, 2006. Tiques des carnivores domestiques en régions Rhône-Alpes, Auvergne, Limousin, Midi-Pyrénées, Aquitaine. Th.Doc.Vét., 2006, Toulouse, 113 p.

Martin V, De Simone L, Lubroth J, Ceccato P, Chevalier V, 2007. Perspectives on using remotely-sensed imagery in predictive veterinary epidemiology and global early warning systems. Geospat Health 2, 3-14.
Michalakes J, Chen S, Dudhia J, Hart L, Klemp J, Middlecoff J, Skamarock W, 2001. Development of a next generation regional weather research and forecast model. Zwieflhofer W, Kreitz N (Eds). World Scientific, pp. 269276.

Mortarino M, Musella V, Costa V, Genchi C, Cringoli G, Rinaldi L, 2008. GIS modeling for canine dirofilariosis risk assessment in Central Italy. Geospat Health 2, 253-261.

Oteo JA, Portillo A, Santibáñez S, Blanco JR, Pérez-Martínez L, Ibarra V, 2006. Cluster of cases of human Rickettsia felis infection from Southern Europe (Spain) diagnosed by PCR. J Clin Microbiol 44, 2669-2671.

Otranto D, Wall R, 2008. New strategies for the control of arthropod vectors of disease in dogs and cats. Med Vet Entomol 22, 291-302.

Parola P, Davoust B, Raoult D, 2005. Tick- and flea-borne rickettsial emerging zoonoses. Vet Res 36, 469-492.

Pérez-Eid C, 2007. Les tiques, identification, biologie, importance médicale et vétérinaire. $\mathrm{Ed} \mathrm{Tec} \mathrm{\&} \mathrm{Doc} \mathrm{Lavoisier,} 314$ pp.

Rinaldi L, Musella V, Biggeri A, Cringoli G, 2006. New insights into the application of geographical information systems and remote sensing in veterinary parasitology. Geospat Health 1, 33-47.

Rinaldi L, Spera G, Musella V, Carbone S, Veneziano V, Iori A, Cringoli G, 2007. A survey of fleas on dogs in Southern Italy. Vet Parasitol 148, 375-378.

Rizzoli A, Neteler M, Rosà R, Versini W, Cristofolini A, Bregoli M, Buckley A, Gould EA, 2007. Early detection of tick-borne encephalitis virus spatial distribution in the province of Trento, Northern Italy. Geospat Health 2, 169176.

Rolain JM, Franc M, Davoust B, Raoult D, 2003. Molecular detection of Bartonella quintana, B. koeblerae, B. henselae, B. clarridgeiae, Rickettsia felis, and Wolbachia pipientis in cat fleas, France. Emerg Infect Dis 9, 338-342.

Savary de Beauregard B, 2003. Contribution à l'étude épidémiologique des maladies vectorielles bactériennes du chat dans le Sud de la France. Th.Doc.Vét, 2003, Toulouse, 100 p. Shaw SE, Day MJ, Birtles RJ, Breitschwerdt EB, 2001. Tickborne infectious diseases of dogs. Trends Parasitol 17, 7480.

Shaw SE, Kenny MJ, Tasker S, Birtles RJ, 2004. Pathogen carriage by the cat flea Ctenocephalides felis (Bouché) in the 
United Kingdom. Vet Microbiol 8,183-188.

Shaw SE, Lerga AI, Williams S, Beugnet F, Birtles RJ, Day MJ, Kenny MJ, 2003. Review of exotic infectious diseases in small animals entering the United Kingdom from abroad diagnosed by PCR. Vet Rec 15, 176-177.

Silveira JA, Passos LM, Ribeiro MF, 2009. Population dynamics of Rhipicephalus sangineus (Latreille, 1806) in Belo Horizonte, Minas Gerais state, Brazil. Vet Parasitol 161, 270-275.

Skamarock WC, Klemp JB, Dudhia J, Gill DO, Barker DM, Duda MG, Huang X-J, Wang W, Powers JG, 2008. A description of the Advanced Research WRF Version 3. NCAR Technical Note, NCAR/TN-475+STR, 126 pp.

Vayssier-Taussat M, Petit E, Franc M, Marotel M, Beugnet F, Boulouis HJ, 2005. Preliminary epidemiological study of the prevalence of Erhlichia spp., Anaplasma phagocytophilum, Babesia spp., Borrelia burgdorferi sensu lato and Rickettsia spp DNA in ticks collected on domestic carnivores in France. Proceedings, Tick Transmitted Pathogen 5th Congress, Neuchatel, Switzerland, September 2005.
Wicker LJ, Skamarock WC, 2002. Time splitting methods for elastic models using forward time schemes. Mon Wea Rev 130, 2088-2097.

Wimberly MC, Baer AD, Yabsley MJ. Enhanced spatial models for predicting the geographic distributions of tick-borne pathogens. Int J Health Geogr 7, 15.

Zahler M, Gothe R, 1995a. Effect of temperature and humidity on egg hatch, moulting and longevity of larvae and nymphs of Dermacentor reticulatus (Ixodidae). Appl Parasitol 36, 53-65.

Zahler M, Gothe R, 1995b. Effect of temperature and humidity on longevity of unfed adults and on oviposition of engorged females of Dermacentor reticulatus (Ixodidae). Appl Parasitol 36, 200-211.

Websites for the Weather Research and Forecasting Model: http://www.wrf-model.org/index.php www.mmm.ucar.edu/mm5 www.nco.ncep.noaa.gov/pmb/products/gfs www.usgs.gov 